\title{
Roles of gangliosides in the differentiation of mouse pluripotent stem cells to neural stem cells and neural cells (Review)
}

\author{
JAE-SUNG RYU ${ }^{1}$, KINARM KO $^{2,3}$, KISUNG KO $^{4}$, JI-SU KIM $^{5}$, SUN-UK KIM $^{5}$, \\ KYU-TAE $\mathrm{CHANG}^{5}$ and YOUNG-KUG CHOO ${ }^{6,7}$ \\ ${ }^{1}$ Stem Cell Research Center, Korea Institute of Bioscience and Biotechnology, Daejeon 34141; \\ ${ }^{2}$ Department of Stem Cell Biology, School of Medicine; ${ }^{3}$ Center for Stem Cell Research, Institute of Advanced \\ Biomedical Science, Konkuk University, Seoul 05029; ${ }^{4}$ Department of Medicine, College of Medicine, Chung-Ang \\ University, Seoul 06974; ${ }^{5}$ National Primate Research Center, Korea Institute of Bioscience and Biotechnology, Cheongju, \\ Chungcheongbuk 28116; ${ }^{6}$ Department of Biological Science, College of Natural Sciences, Wonkwang University; \\ ${ }^{7}$ Institute for Glycoscience, Wonkwang University, Iksan, Jeollabuk 54538, Republic of Korea
}

Received June 14, 2016; Accepted April 12, 2017

DOI: $10.3892 / \mathrm{mmr} .2017 .6719$

\begin{abstract}
Glycosphingolipids are important components of the outer layer of the plasma membrane in the majority of eukaryotic cells. Specifically, gangliosides are sialic acid-containing glycosphingolipids that participate in cell-cell recognition, adhesion, proliferation, differentiation and signal transduction, and are integral components of cell surface microdomains and lipid rafts. Stem cells are defined functionally as cells that have the capacity to self-renewal and differentiate to generate various cell types. Due to different synthesis patterns and locations of gangliosides, they have been used as molecular markers of stem cells. The current review describes the presence of gangliosides in various types of mouse stem cells, including pluripotent stem cells (embryonic stem cells and induced pluripotent stem cells) and neural stem cells, and the functional roles of gangliosides in various processes, including cell proliferation and neural differentiation. Thus, this review will aid the understanding of
\end{abstract}

Correspondence to: Dr Kyu-Tae Chang, National Primate Research Center, Korea Institute of Bioscience and Biotechnology, 30 Yeongudanji-ro, Ochang, Cheongwon, Cheongju, Chungcheongbuk 28116, Republic of Korea

E-mail: changkt@kribb.re.kr

Professor Young-Kug Choo, Department of Biological Science, College of Natural Sciences, Wonkwang University, 460 Iksandae-ro, Iksan, Jeollabuk 54538, Republic of Korea

E-mail: ykchoo@wku.ac.kr

Abbreviations: ESCs, embryonic stem cells; iPSCs, induced pluripotent stem cells; MEF, mouse embryonic fibroblast; NSCs, neural stem cells

Key words: gangliosides, mouse pluripotent stem cells, mouse neural stem cells, mouse neural cells, differentiation, marker gangliosides patterns and functions in mouse stem cells, and outline markers for the identification of stem cells.

\section{Contents}

1. Introduction

2. Stage-specific embryonic antigens (SSEA)

3. Biosynthesis of gangliosides

4. Expression patterns of gangliosides in mouse pluripotent stem cells

5. Expression patterns of gangliosides in mouse neural stem cells ( $\mathrm{mNSCs}$ )

6. Expression patterns of gangliosides in differentiated neural cells

7. Conclusion

\section{Introduction}

Gangliosides belong to a heterogeneous family of lipids known as glycosphingolipids, which are ubiquitously expressed in vertebrate cells, and are particularly abundant in the central nervous system (1). Within mammalian cells, gangliosides are predominantly localized on the plasma membrane $(2,3)$, where they form cell surface microdomains, including caveolae, lipid rafts, and glycolipid-enriched microdomains or cholesterol $(2,4,5)$. Specifically, gangliosides are established to have various functions, including in cell proliferation, differentiation, immune response, adhesion, migration, apoptosis, and cell-cell and cell-substratum interactions (6). Gangliosides are classified by the presence of one or more sialic acid residues linked to different galactose and/or sialic acid residues, and are classified into asialo (o)-, a-, b- and c-series gangliosides, respectively (7).

Stem cells are widelyusedduring research intodevelopmental processes and offer tremendous potential in clinical applications for transplantation and tissue regeneration therapies (8). As they are undifferentiated, stem cells, specifically embryonic 
stem cells (ESCs), have a high potential for proliferation (self-renewal) and the capacity to differentiate into various distinct cell types (multipotency or pluripotency) (9). Induced pluripotent stem cells (iPSCs) have been generated from mouse fibroblasts via retroviral introduction of four defined transcription factors: $P O U$ domain, class 5, transcription factor 1 (Oct-4), SRY (sex determining region Y)-box 2 (Sox-2), c-Myc and Kruppel-like factor 4 (Klf-4) (10). Induction of pluripotency can be also achieved in mouse spermatogonial stem cells by self-reprogramming process $(11,12)$. Reprogrammed pluripotent stem cells, such as iPSCs and germline-derived pluripotent stem cells, are indistinguishable from ESCs in terms of morphology, self-renewal, expression of ESC markers, and their differentiation ability $(10,11,13,14)$. Neural stem cells (NSCs) are known to be self-renewing, multipotent cells that can differentiate into brain-forming cells, such as neurons and glial cells (astrocytes and oligodendrocytes) (15). NSCs highly express nestin, Musashi RNA-binding protein 1 (Musashi-1), Sox-2 and paired box 6 (Pax-6).

\section{Stage-specific embryonic antigens (SSEA)}

Carbohydrate-associated molecules are known to be involved in controlling cell surface interactions during development. Specifically, SSEA series were originally identified by defined carbohydrate epitopes associated with the lactoand globo-series glycolipids, such as SSEA-1, SSEA-3 and SSEA-4 $(16,17)$. These SSEA series were expressed in various tissues, cancer and cancer stem cells (18-23). Notably, SSEA series are present in pluripotent stem cells, such as ESCs and iPSCs. SSEA-1 (also termed CD15 and Lewis $\mathrm{x}$ ) is present on the surface of murine embryos at the pre-implantation stage, in mouse germ cells and on the surface of teratocarcinoma stem cells (24). SSEA-1 is also produced in the thyroid, oviduct epithelium, endometrium and epididymis, and in certain areas of the brain and kidney tubules in adults $(18,25)$. SSEA-1 production increases upon differentiation in human cells and decreases during differentiation in mice.

SSEA-3 and SSEA-4 are synthesized during oogenesis and are present in the membranes of oocytes, zygotes and early cleavage-stage embryos in human $(24,26)$. They are present in undifferentiated primate ESCs, human embryonic germ cells, teratocarcinoma stem cells and ESCs (27).

\section{Biosynthesis of gangliosides}

Ganglioside biosynthesis and degradation occurs through several events: i) De novo ganglioside biosynthesis in the endoplasmic reticulum and Golgi apparatus, followed by vesicular sorting to the plasma membrane; ii) enzyme-assisted chemical modifications of molecules at the plasma membrane level; iii) internalization of gangliosides via endocytosis and recycling to the plasma membrane; iv) direct glycosylations following sorting from endosomes to the Golgi apparatus; v) degradation at the late endosomal/lysosomal level with formation of fragments of sugars (glucose, galactose, hexosamine, sialic acid) and lipids (ceramide, sphingosine, fatty acid); vi) metabolic recycling of these fragments for biosynthetic purposes (salvage pathways); and vii) further degradation of fragments to waste products (Fig. 1) (28).
Ceramides, a group of higher glycosphingolipids, are glucosylated by a glucosyl-transferase (29-31). An uncharacterized flippase enzyme caused Glc-ceramide to flip to the lumenal side of the cis-Golgi stack, where further glycosylations takes place. The first glycosylation, catalyzed by lactosyl (Lac)-ceramide synthase is galactosylation of Glc-ceramide to Lac-ceramide (Fig. 2) (32-34). Lac-ceramide is sialosylated to produce GM3, GD3 and GT3 molecules via the action of three sialyltransferases (SAT) I, II and III, each recognizing their specific acceptor substrate $(35,36)$. GM3, GD3 and GT3 are the starting points for the 'a-series', 'b-series' and 'c-series' gangliosides, respectively. In each ganglioside series, $\mathrm{N}$-acetyl-galactosaminyltransferase, galactosyl-transferase and SAT IV, in sequence, add an N-acetylgalactosamine, galactose and sialic acid group to the gangliosides, respectively, to produce more complex gangliosides. Further sialosylations can be performed by SAT V. From Lac-ceramide a further group of glycosphingolipids ('O-series') can be produced by the sequential action of $\mathrm{N}$-acetyl-galactosaminyltransferase, galactosyl-transferase and sialyl-transferase IV and V, producing asialo-GM2 (GA2), asialo-GM1 (GA1), and gangliosides GM1b, GD1c and GD1 $\alpha$ (28).

\section{Expression patterns of gangliosides in mouse pluripotent stem cells}

Mouse embryonic stem cells (mESCs) are derived from the inner cell mass of blastocysts (37). Established mESCs express various carbohydrate antigens, including glycolipids. Among those, SSEA-1 is the most well-established specific marker.

In E14 and Oct-4 promoter-EGFP (OG2) mESCs, small amounts of a-series gangliosides, GM3, GM1 and GD1a, were detected by high-performance thin-layer chromatography and immunocytochemistry analysis $(38,39)$. Furthermore, in TC-1 mESCs, only glucosylceramide and lactosylceramide were present (40); however, J1 mESCs contained GM3, GM1, and GD3 (Fig. 3A) (41-43). Furthermore, 9-O acetyl GD3 was detected in 129S6/B6-F1/DsRed.T3 mESCs (44). GM3 and GD3 are known to be involved in cell adhesion and proliferation via mitogen-activated protein kinase (MAPK) /extracellular signal-regulated kinases (ERK) 1/2 phosphorylation (Table I) $(41,42,45,46)$. Specifically, small hairpin RNA knock-down of UDP-glucose ceramide glucosyltransferase $(U G C G)$ to reduce glucosylceramide synthesis was demonstrated to inhibit activation of the Ras-MAPK pathway and cell proliferation (41).

OG2 mouse embryonic fibroblast (MEF) and mESCs produce GM3, GM1, and GD1a, but GM1 is not found in OG2 MEF-derived iPSCs (Fig. 3B) (39). Analysis of the cell proliferation rate in OG2 mESCs and iPSCs revealed that iPSCs have a lower proliferation than that of mESCs. GM1 is known to affect cell proliferation via the ERK 1/2-MAPK pathway and protects against apoptosis in various cell types (Table I) $(39,42,47-49)$.

\section{Ganglioside patterns in mouse neural stem cells (mNSCs)}

NSCs, also referred to as multipotent neural progenitor cells, can differentiate to cells of the neural linage, including neurons and glial cells (astrocytes and oligodendrocytes) (50). The 
Table I. Function and role of gangliosides in mouse stem cells.

Ganglioside

GM3

GM1

GD1a

GD3

GT1b

GQ1b

SSEA-1

SSEA-3

SSEA-4

Function/role

Cell adhesion, proliferation and neural differentiation, induction of neural precursor cells, facilitates neurite formation, neural maturation, activates ERK1/2 MAPK phosphorylation

Promotes neural differentiation, regulate neurogenesis and regeneration, protects against apoptosis, cell proliferation, activates ERK1/2 MAPK phosphorylation

Induction of early neural differentiation

Induction of early neural differentiation, brain development, cell adhesion and proliferation, neural maturation, facilitates neurite formation, activates ERK1/2-MAPK phosphorylation, induction of neural precursor cells, neural stem cell markers

Necessary for induction neural differentiation, enhances actin-rich dendrite generation, increased in brain synapses

Neurite outgrowth during early neural differentiation, neural differentiation through the ERK1/2-MAPK pathway

Expression on pre- and post-implantation mouse embryo and teratocarcinoma cells, expression in thyroid tissue, expression in human renal tumors

Expression in human teratocarcinoma cells, expression in colorectal cancer, significant markers for breast cancer stem cells

Expression in human teratocarcinoma cells, expression in oral cancer cell, expression in basaloid lung cancer

SSEA, stage-specific embryonic antigen; ERK, extracellular signal-regulated kinase; MAPK, mitogen-activated protein kinase.

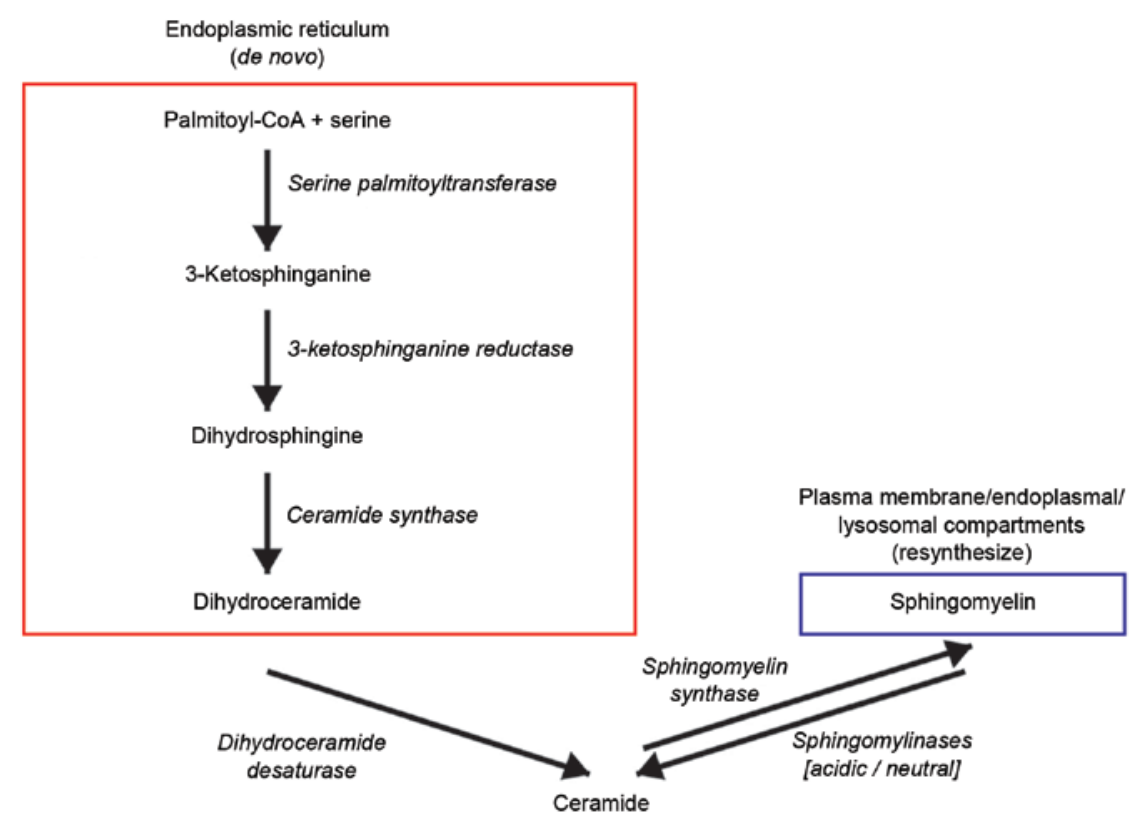

Figure 1. Biochemical pathway of ceramide generation and metabolism. Enzymes are shown in italics. Ceramide is derived from two main pathways operating in different cellular compartments: De novo synthesis from serine and palmitoyl CoA; and hydrolysis of membrane-derived sphingomyelin.

NSCs highly express nestin, Musashi-1 and Sox-2; however, these marker molecules are intracellular or nuclear proteins. Several studies demonstrated that there are high levels of b-series gangliosides in NSCs (51-55). GD3 is a b-series disialoganglioside that is frequently detected in vertebrate embryos and immature proliferative cells $(56,57)$. Particularly, GD3 and 9-O acetyl GD3 have been biochemically detected in mNSCs $(44,53,58)$. GD3 is present in the subventricular zone of the lateral ventricle where NSCs are localized $(59,60)$.
Furthermore, GD3 expression in mouse neuroepithelial cells is enriched in NSCs, radial glia, embryonic-, postnatal-, and adult-NSCs (Fig. 3C) $(53,58,61)$. Furthermore, NSCs differentiated from mESCs also express GD3 (unpublished data) (Fig. 3A).

The GD3 concentration is known to be high in embryonic brains, which predominantly consist of undifferentiated neural progenitor cells; however, the concentration in the brain rapidly decreases after birth (62). It has been demonstrated 


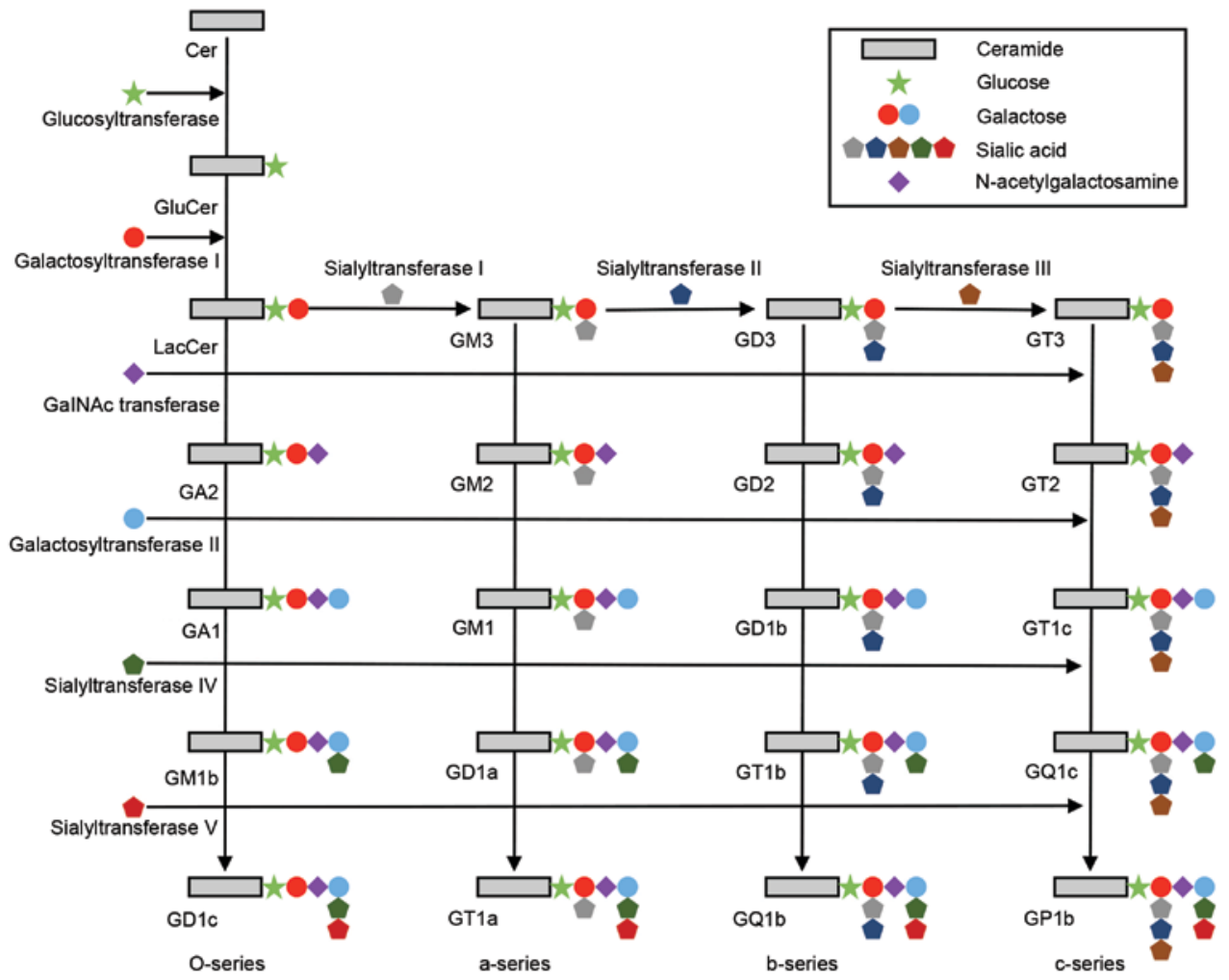

Figure 2. Schematic diagram of the ganglioside biosynthetic pathways. The o-series (GA2, GA1, GM1b and GD1c), the a-series (GM3, GM2, GM1, GD1a and GT1a), the b-series (GD3, GD2, GD1b, GT1b and GQ1b) and the c-series (GT3, GT2, GT1c, GQ1c and GP1c), and the corresponding glucosyltransferase, galactosyltransferases, GalNAc transferase, and sialyltransferases are shown. Cer, ceramide.

A
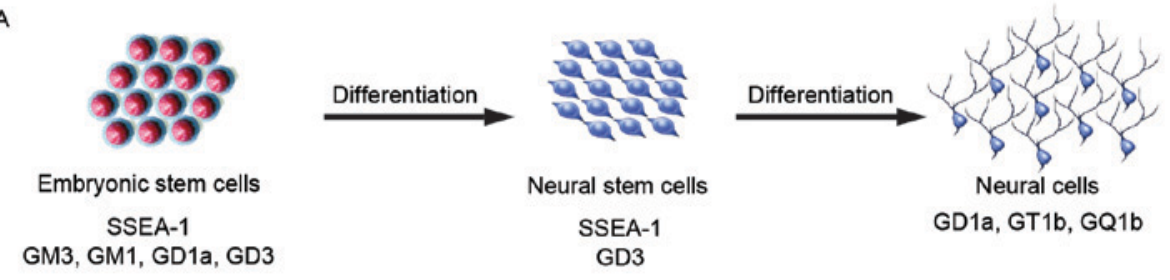

B

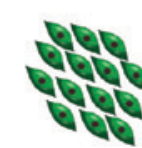

Fibroblast

GM3, GM2, GD1a

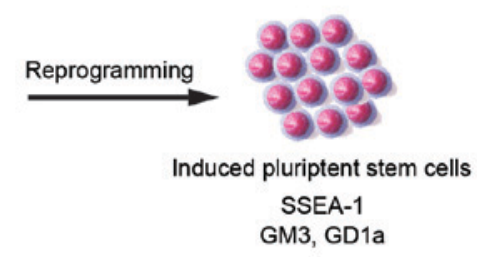

C

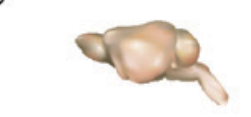

Fetal brain (E14) GM3, GM1, GD3, GD1a, GD2, GD1b, GT1b, GQ1

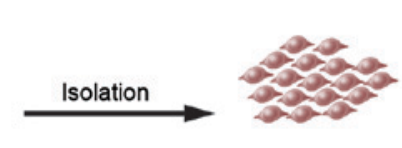

Neural stem cells

SSEA-1

GD3

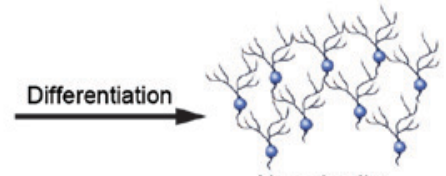

Neural cells

GD1a, GT1b, GQ1b

Figure 3. Expression of gangliosides in various mouse stem cells. (A) Patterns of ganglioside synthesis during neural cell differentiation from mouse embryonic stem cells. (B) Changes in ganglioside synthesis patterns from fibroblast to induced pluripotent stem cells during reprogramming. (C) Ganglioside synthesis patterns in fetal brain, isolated neural stem cells from fetal brain and differentiated neural cells. SSEA, stage-specific embryonic antigen; E14, embryonic day 14.

that NSCs derived from GD3-synthase knockout mice could not be maintained in in vitro culture (55); thus, it is speculated that GD3 has a major role in the maintenance of NSCs $(51,54,63)$. It has been reported that when the 
GD3 level was reduced by an inhibitor of glucosylceramide synthesis, basic fibroblast growth factor-induced proliferation was repressed in primary mNSCs. Additionally, GD3 interacts with epidermal growth factor receptor (EGFR) $(55,64)$. These finding imply that GD3 may induce early neural precursor cell differentiation and neurite formation (Table I) $(41,43)$.

\section{Expression patterns of gangliosides in differentiated neural cells}

The pattern of ganglioside synthesis changes dramatically during nervous system development (65-67). Thus, gangliosides, including sulfatide (for the myelin sheath in the peripheral and central nerve system), galactosylceramide (for oligodendrocytes) and A2B5 (c-series gangliosides; for neural stem cells, oligodendrocytes, and astrocytes) are considered to be useful as differentiation markers of specific neural lineages (68). It was reported previously that the GD3 level is high in the brain and is involved in embryonic brain development; however, its concentration rapidly decreases during neural development, whereas other gangliosides, including GD1a, GT1b, and GQ1b, increase during aging and neural development (62). In addition, it was demonstrated that correlative changes of ganglioside composition accompany normal development in vitro and in vivo. Furthermore, b-series gangliosides, including GT1b and GQ1b, are present in mouse neuroepithelial cells $(58,69)$.

Our previous studies demonstrated that GD3, GT1b, and GQ1b are present in cells during retinoic acid-induced neural differentiation of mESCs and embryonic carcinoma cells (Fig. 3A) (42,43). A number of approaches have been reported to determine the role of gangliosides during neural differentiation (70,71). Overproduction of gangliosides can facilitate neurite formation, which is part of the neural maturation process (43). By contrast, knock-down of $U g c g$ was reported to result in a decrease in the neural differentiation rate of mESCs and human dental pulp-derived mesenchymal stem cells $(41,72)$. Therefore, these gangliosides have important regulatory roles in neural differentiation in vitro $(41-43,73)$.

GD3 is involved in the early neural differentiation and maturation process $(63,74)$, while GD1a induces early neural differentiation (43). By contrast with GD3, GT1b is necessary for the induction of neural differentiation and drastically enhances actin-rich dendrite generation (42,75). Furthermore, it GT1b syntheses is increased in brain synapses (74). GQ1b promotes neurite outgrowth during early neural differentiation via the ERK 1/2-MAPK pathway (Table I) $(43,73,76)$.

\section{Conclusion}

Gangliosides are located on the plasma membrane and have roles in various functions of mouse stem cells. As described above, specific gangliosides are detected in mESCs, mouse iPSCs, mNSCs and differentiated neural cells. These gangliosides regulate cell proliferation and differentiation via the MAPK-ERK 1/2 pathway. Furthermore, gangliosides have been demonstrated to be useful marker molecules for detecting or sorting mouse stem cells and differentiated neural cells. Nevertheless, the functional roles of gangliosides during cellular differentiation and proliferation require further investigation. Identification of the gangliosides present in stem cells should be performed to thoroughly characterize marker gangliosides, and contribute to progression in basic stem cell research and clinical applications.

\section{Acknowledgements}

This paper was supported by Wonkwang University (Iksan, Korea) in 2015.

\section{References}

1. Schengrund CL: The role(s) of gangliosides in neural differentiation and repair: A perspective. Brain Res Bull 24: 131-141, 1990.

2. Hakomori S: Structure, organization, and function of glycosphingolipids in membrane. Curr Opin Hematol 10: 16-24, 2003.

3. Yu RK, Nakatani Y and Yanagisawa M: The role of glycosphingolipid metabolism in the developing brain. J Lipid Res 50 (Suppl): S440-S445, 2009.

4. Anderson RG: The caveolae membrane system. Annu Rev Biochem 67: 199-225, 1998.

5. Simons K and Toomre D: Lipid rafts and signal transduction. Nat Rev Mol Cell Biol 1: 31-39, 2000.

6. Hakomori S, Yamamura S and Handa AK: Signal transduction through glyco(sphingo)lipids. Introduction and recent studies on glyco(sphingo)lipid-enriched microdomains. Ann N Y Acad Sci 845: 1-10, 1998.

7. Yu RK, Tsai YT, Ariga T and Yanagisawa M: Structures, biosynthesis, and functions of gangliosides-an overview. J Oleo Sci 60: 537-44, 2011.

8. Fortier LA: Stem cells: Classifications, controversies, and clinical applications. Vet Surg 34: 415-423, 2005.

9. Smith AG: Embryo-derived stem cells: Of mice and men. Annu Rev Cell Dev Biol 17: 435-462, 2001.

10. Takahashi $\mathrm{K}$ and Yamanaka $\mathrm{S}$ : Induction of pluripotent stem cells from mouse embryonic and adult fibroblast cultures by defined factors. Cell 126: 663-676, 2006.

11. Ko K, Tapia N, Wu G, Kim JB, Bravo MJ, Sasse P, Glaser T, Ruau D, Han DW, Greber B, et al: Induction of pluripotency in adult unipotent germline stem cells. Cell Stem Cell 5: 87-96, 2009.

12. Ko K, Araúzo-Bravo MJ, Kim J, Stehling M and Schöler HR: Conversion of adult mouse unipotent germline stem cells into pluripotent stem cells. Nature Protoc 5: 921-928, 2010.

13. Kim JB, Zaehres H, Wu G, Gentile L, Ko K, Sebastiano V, Araúzo-Bravo MJ, Ruau D, Han DW, Zenke M and Schöler HR: Pluripotent stem cells induced from adult neural stem cells by reprogramming with two factors. Nature 454: 646-650, 2008.

14. Kim JB, Sebastiano V, Wu G, Araúzo-Bravo MJ, Sasse P, Gentile L, Ko K, Ruau D, Ehrich M, van den Boom D, et al: Oct4-induced pluripotency in adult neural stem cells. Cell 136: 411-419, 2009.

15. Molyneaux BJ, Arlotta P, Menezes JR and Macklis JD: Neuronal subtype specification in the cerebral cortex. Nat Rev Neurosci 8: 427-437, 2007.

16. Shamblott MJ, Axelman J, Wang S, Bugg EM, Littlefield JW, Donovan PJ, Blumenthal PD, Huggins GR and Gearhart JD: Derivation of pluripotent stem cells from cultured human primordial germ cells. Proc Natl Acad Sci USA 95: 13726-13731, 1998.

17. Solter D and Knowles BB: Monoclonal antibody defining a stage-specific mouse embryonic antigen (SSEA-1). Proc Natl Acad Sci USA 75: 5565-5569, 1978.

18. Xu J, Hardin H, Zhang R, Sundling K, Buehler D and Lloyd RV: Stage-specific embryonic antigen-1 (SSEA-1) expression in thyroid tissues. Endocr Pathol 27: 271-275. 2016.

19. Liebert M, Jaffe R, Taylor RJ, Ballou BT, Solter D and Hakala TR: Detection of SSEA-1 on human renal tumors. Cancer 59: 1404-1408, 1987.

20. Suzuki Y, Haraguchi N, Takahashi H, Uemura M, Nishimura J, Hata T, Takemasa I, Mizushima T, Ishii H, Doki Y, et al: SSEA-3 as a novel amplifying cancer cell surface marker in colorectal cancers. Int J Oncol 42: 161-167, 2013. 
21. Cheung SK, Chuang PK, Huang HW, Hwang-Verslues WW, Cho $\mathrm{CH}$, Yang WB, Shen CN, Hsiao M, Hsu TL, Chang CF and Wong CH: Stage-specific embryonic antigen-3 (SSEA-3) and $\beta 3$ GalT5 are cancer specific and significant markers for breast cancer stem cells. Proc Natl Acad Sci USA 113: 960-965, 2016.

22. Noto Z, Yoshida T, Okabe M, Koike C, Fathy M, Tsuno H, Tomihara K, Arai N, Noguchi M and Nikaido T: CD44 and SSEA-4 positive cells in an oral cancer cell line HSC-4 possess cancer stem-like cell characteristics. Oral Oncol 49: 787-795, 2013.

23. Gottschling S, Jensen K, Warth A, Herth FJ, Thomas M, Schnabel PA and Herpel E: Stage-specific embryonic antigen-4 is expressed in basaloid lung cancer and associated with poor prognosis. Eur Respir J 41: 656-663, 2013.

24. Knowles BB, Aden DP and Solter D: Monoclonal antibody detecting a stage-specific embryonic antigen (SSEA-1) on preimplantation mouse embryos and teratocarcinoma cells. Curr Top Microbiol Immunol 81: 51-53, 1978.

25. Fox N, Damjanov I, Martinez-Hernandez A, Knowles BB and Solter D: Immunohistochemical localization of the early embryonic antigen (SSEA-1) in postimplantation mouse embryos and fetal and adult tissues. Dev Biol 83: 391-398, 1981.

26. Fox N, Shevinsky L, Knowles BB, Solter D and Dawjanov I: Distribution of murine stage-specific embryonic antigens in the kidneys of three rodent species. Exp Cell Res 140: 331-339, 1982.

27. Kannagi R, Cochran NA, Ishigami F, Hakomori S, Andrews PW, Knowles BB and Solter D: Stage-specific embryonic antigens (SSEA-3 and -4) are epitopes of a unique globo-series ganglioside isolated from human teratocarcinoma cells. EMBO J 2 : 2355-2361, 1983

28. Tettamanti G: Ganglioside/glycosphingolipid turnover: New concepts. Glycoconj J 20: 301-317, 2004.

29. Basu S, Kaufman B and Roseman S: Enzymatic synthesis of glucocerebroside by a glucosyltransferase from embryonic chicken brain. J Biol Chem 248: 1388-1394, 1973.

30. Ichikawa S, Sakiyama H, Suzuki G, Hidari KI and Hirabayashi Y: Expression cloning of a cDNA for human ceramide glucosyltransferase that catalyzes the first glycosylation step of glycosphingolipid synthesis. Proc Natl Acad Sci USA 93: 4638-4643, 1996.

31. Paul P, Kamisaka Y, Marks DL and Pagano RE: Purification and characterization of UDP-glucose: Ceramide glucosyltransferase from rat liver Golgi membranes. J Biol Chem 271: 2287-2293, 1996.

32. Basu S, Kaufman B and Roseman S: Enzymatic synthesis of ceramide-glucose and ceramide-lactose by glycosyltransferases from embryonic chicken brain. J Biol Chem 243: 5802-5804, 1968.

33. Nomura $\mathrm{T}$, Takizawa $\mathrm{M}$, Aoki J, Arai $\mathrm{H}$, Inoue $\mathrm{K}$, Wakisaka $\mathrm{E}$, Yoshizuka N, Imokawa G, Dohmae N, Takio K, et al: Purification, cDNA cloning, and expression of UDP-Gal: Glucosylceramide beta-1,4-galactosyltransferase from rat brain. J Biol Chem 273: 13570-13577, 1998.

34. Sundaram KS and Lev M: Purification and activation of brain sulfotransferase. J Biol Chem 267: 24041-24044, 1992.

35. Huwiler A, Kolter T, Pfeilschifter J and Sandhoff K: Physiology and pathophysiology of sphingolipid metabolism and signaling. Biochim Biophys Acta 1485: 63-99, 2000

36. Kolter T, Proia RL and Sandhoff K: Combinatorial ganglioside biosynthesis. J Biol Chem 277: 25859-25862, 2002.

37. Martin GR: Isolation of a pluripotent cell line from early mouse embryos cultured in medium conditioned by teratocarcinoma stem cells. Proc Natl Acad Sci USA 78: 7634-7638, 1981.

38. Kimber SJ, Brown DG, Pahlsson P and Nilsson B: Carbohydrate antigen expression in murine embryonic stem cells and embryos. II. Sialylated antigens and glycolipid analysis. Histochem J 25 628-641, 1993.

39. Ryu JS, Chang KT, Lee JT, Lim MU, Min HK, Na YJ, Lee SB Moussavou G, Kim SU, Kim JS, et al: Ganglioside GM1 influences the proliferation rate of mouse induced pluripotent stem cells. BMB Rep 45: 713-718, 2012.

40. Yamashita T, Wada R, Sasaki T, Deng C, Bierfreund U, Sandhoff K and Proia RL: A vital role for glycosphingolipid synthesis during development and differentiation. Proc Natl Acad Sci USA 96: 9142-9147, 1999.

41. Jung JU, Ko K, Lee DH, Ko K, Chang KT and Choo YK: The roles of glycosphingolipids in the proliferation and neural differentiation of mouse embryonic stem cells. Exp Mol Med 41: 935-345, 2009.
42. Kwak DH, Yu K, Kim SM, Lee DH, Kim SM, Jung JU, Seo JW, Kim N, Lee S, Jung KY, et al: Dynamic changes of gangliosides expression during the differentiation of embryonic and mesenchymal stem cells into neural cells. Exp Mol Med 38: 668-676, 2006.

43. Lee DH, Koo DB, Ko K, Ko K, Kim SM, Jung JU, Ryu JS, Jin JW, Yang HJ, Do SI, et al: Effects of daunorubicin on ganglioside expression and neuronal differentiation of mouse embryonic stem cells. Biochem Biophys Res Commun 362: 313-318, 2007.

44. Azevedo-Pereira RL, Morrot A, Machado GS, Paredes BD, Rodrigues Dde C, de Carvalho AC and Mendez-Otero R: Expression of ganglioside 9-O acetyl GD3 in undifferentiated embryonic stem cells. Cell Biol Int 39: 121-127, 2015.

45. Cheresh DA, Pierschbacher MD, Herzig MA and Mujoo K: Disialogangliosides GD2 and GD3 are involved in the attachment of human melanoma and neuroblastoma cells to extracellular matrix proteins. J Cell Biol 102: 688-696, 1986.

46. Kwak DH, Rho YI, Kwon OD, Ahan SH, Song JH, Choo YK, Kim SJ, Choi BK and Jung KY: Decreases of ganglioside GM3 in streptozotocin-induced diabetic glomeruli of rats. Life Sci 72: 1997-2006, 2003

47. Duan JG, Xiang T, Chen H and Liu M: Role of extrinsic ganglioside GM1 in proliferation and differentiation of neural stem cells. Sichuan Da Xue Xue Bao Yi Xue Ban 38: 260-263, 2007 (In Chinese).

48. Gouni-Berthold I, Seul C, Ko Y, Hescheler J and Sachinidis A: Gangliosides GM1 and GM2 induce vascular smooth muscle cell proliferation via extracellular signal-regulated kinase $1 / 2$ pathway. Hypertension 38: 1030-1037, 2001

49. Nishio M, Tajima O, Furukawa K, Urano T and Furukawa K: Over-expression of GM1 enhances cell proliferation with epidermal growth factor without affecting the receptor localization in the microdomain in PC12 cells. Int J Oncol 26: 191-199, 2005.

50. Lee SW, Lee HJ, Hwang HS, Ko K, Han DW and Ko K: Optimization of Matrigel-based culture for expansion of neural stem cells. Anim Cells Syst 19: 175-180, 2015.

51. Itokazu Y, Kato-Negishi M, Nakatani Y, Ariga T and Yu RK: Effects of amyloid $\beta$-peptides and gangliosides on mouse neural stem cells. Neurochem Res 38: 2019-2027, 2013.

52. Klassen H, Schwartz MR, Bailey AH and Young MJ: Surface markers expressed by multipotent human and mouse neural progenitor cells include tetraspanins and non-protein epitopes. Neurosci Lett 312: 180-182, 2001.

53. Nakatani Y, Yanagisawa M, Suzuki Y and Yu RK: Characterization of GD3 ganglioside as a novel biomarker of mouse neural stem cells. Glycobiology 20: 78-86, 2010.

54. Wang J, Cheng A, Wakade C and Yu RK: Ganglioside GD3 is required for neurogenesis and long-term maintenance of neural stem cells in the postnatal mouse brain. J Neurosci 34: 13790-13800, 2014.

55. Wang $\mathbf{J}$ and Yu RK: Interaction of ganglioside GD3 with an EGF receptor sustains the self-renewal ability of mouse neural stem cells in vitro. Proc Natl Acad Sci USA 110: 19137-19142, 2013

56. Irvine RA and Seyfried TN: Phylogenetic conservation of ganglioside GD3 expression during early vertebrate ontogeny. Comp Biochem Physiol B Biochem Mol Biol 109: 603-612, 1994

57. Seyfried TN and Yu RK: Ganglioside GD3: Structure, cellular distribution, and possible function. Mol Cell Biochem 68: 3-10, 1985.

58. Yanagisawa M, Nakamura $\mathrm{K}$ and Taga T: Roles of lipid rafts in integrin-dependent adhesion and gp130 signalling pathway in mouse embryonic neural precursor cells. Genes Cells 9: 801-809, 2004.

59. Doetsch F, Caillé I, Lim DA, Garcia-Verdugo JM and Alvarez-Buylla A: Subventricular zone astrocytes are neural stem cells in the adult mammalian brain. Cell 97: 703-716, 1999.

60. Goldman JE, Hirano M, Yu RK and Seyfried TN: GD3 ganglioside is a glycolipid characteristic of immature neuroectodermal cells. J Neuroimmunol 7: 179-192, 1984.

61. Cammer W and Zhang H: Ganglioside GD3 in radial glia and astrocytes in situ in brains of young and adult mice. J Neurosci Res 46: 18-23, 1996.

62. Ngamukote S, Yanagisawa M, Ariga T, Ando S and Yu RK: Developmental changes of glycosphingolipids and expression of glycogenes in mouse brains. J Neurochem 103: 2327-2341, 2007.

63. Liu Y, Li R and Ladisch S: Exogenous ganglioside GD1a enhances epidermal growth factor receptor binding and dimerization. J Biol Chem 279: 36481-36489, 2004. 
64. Yanagisawa M, Nakamura K and Taga T: Glycosphingolipid synthesis inhibitor represses cytokine-induced activation of the Ras-MAPK pathway in embryonic neural precursor cells. J Biochem 138: 285-291, 2005.

65. Bouvier JD and Seyfried TN: Ganglioside composition of normal and mutant mouse embryos. J Neurochem 52: 460-466, 1989.

66. Yu RK: Development regulation of ganglioside metabolism Prog Brain Res 101: 31-44, 1994.

67. Yu RK, Macala LJ, Taki T, Weinfield HM and Yu FS: Developmental changes in ganglioside composition and synthesis in embryonic rat brain. J Neurochem 50: 1825-1829, 1988.

68. Yanagisawa M and Yu RK: The expression and functions of glycoconjugates in neural stem cells. Glycobiology 17: 57R-74R, 2007.

69. Yanagisawa M, Taga T, Nakamura K, Ariga T and Yu RK: Characterization of glycoconjugate antigens in mouse embryonic neural precursor cells. J Neurochem 95: 1311-1320, 2005.

70. Moussavou G, Kwak DH, Lim MU, Kim JS, Kim SU, Chang KT and Choo YK: Role of gangliosides in the differentiation of human mesenchymal-derived stem cells into osteoblasts and neuronal cells. BMB Rep 46: 527-532, 2013.

71. Lee SH, Kwak DH, Ryu JS, Lim MU, Kim JS, Chang KT and Choo YK: Differential expression pattern of gangliosides during the differentiation of human dental pulp-derived mesenchymal stem cells into dopaminergic neural-like cells. Anim Cells Syst 18: 210-216, 2014.
72. Ryu JS, Ko K, Lee JW, Park SB, Byun SJ, Jeong EJ, Ko K and Choo YK: Gangliosides are involved in neural differentiation of human dental pulp-derived stem cells. Biochem Biophys Res Commun 387: 266-271, 2009.

73. Kwak DH, Jin JW, Ryu JS, Ko K, Lee SD, Lee JW, Kim JS, Jung KY, Ko K, Ma JY, et al: Regulatory roles of ganglioside GQ1b in neuronal cell differentiation of mouse embryonic stem cells. BMB Rep 44: 799-804, 2011.

74. Vinson M, Strijbos PJ, Rowles A, Facci L, Moore SE, Simmons DL and Walsh FS: Myelin-associated glycoprotein interacts with ganglioside GT1b. A mechanism for neurite outgrowth inhibition. J Biol Chem 276: 20280-20285, 2001.

75. Osanai T, Kotani M, Yuen CT, Kato H, Sanai Y and Takeda S: Immunohistochemical and biochemical analyses of GD3, GT1b, and GQ1b gangliosides during neural differentiation of P19 EC cells. FEBS Lett 537: 73-78, 2003.

76. Tsuji S, Arita M and Nagai Y: GQ1b, a bioactive ganglioside that exhibits novel nerve growth factor (NGF)-like activities in the two neuroblastoma cell lines. J Biochem 94: 303-306, 1983. 